\section{Pharmacists' Roles in Critical Care: Environmental Scan of Current Practices in Canadian Intensive Care Units}

Clinical pharmacists' practice in critical care has grown and developed independently in different parts of Canada, guided largely by international research and position papers. ${ }^{1-3}$ The association of positive patient outcomes with the involvement of clinical pharmacists is well known. ${ }^{4}$ An environmental scan of current Canadian practices is not available in the published literature. A nonanonymous survey, consisting of 14 groups of open-form questions, was distributed by e-mail to all members of the Canadian Society of Hospital Pharmacists' Critical Care Practice Speciality Network in March 2017 (see Appendix 1, available from https://www.cjhponline.ca/index.php/cjhp/issue/view/155/showToc). A follow-up reminder to potential participants working in critical care was conducted by telephone.

Respondents from 31 centres (Table 1), representing 54 of a possible 180 intensive care units (ICUs), provided input. Institution size, setting, region, and pharmacist training levels did not significantly affect any of the survey responses. Most respondents $(22[71 \%])$ practised in a tertiary care centre, 28 (90\%) in mixed medical-surgical units, and $27(87 \%)$ in closed intensivist-managed units. The mean ICU size was 21 beds (median 20, range 6-44, interquartile range [IQR] 12-27), and the mean equivalent patient load per full-time equivalent pharmacist $^{5}$ was 13 (median 12, range 6-23, IQR 10-17). A group of pharmacists shared ICU coverage in 24 (77\%) of the centres, and a tiered team combining advanced-training and entry-to-practice pharmacists was reported for 14 (45\%) of the centres. Overall, 9 (29\%) of the centres reported that their critical care pharmacy practitioners had received advanced training with either a postbaccalaureate Doctor of Pharmacy (PharmD) or a Master's degree, and 12 (39\%) of the centres required an entryto-practice degree as the minimum educational level to practise in the ICU. Pharmacists had higher credentials in locations where a postbaccalaureate PharmD program had been in existence for longer than 10 years. Clinical pharmacists provided coverage for $8 \mathrm{~h} /$ day in $28(90 \%)$ of the centres and for 5 days a week in 26 (84\%) of the centres, with a mean of $4 \mathrm{~h}$ (range 3-8 h) devoted specifically to rounds. The remaining pharmacist time was devoted to either drug distribution or clinical coverage in noncritical care areas.

Consistent-format patient care rounds were reported by $17(55 \%)$ of the centres, with another $11(35 \%)$ reporting that the specific format of rounds was determined by the attending
Table 1. Locations of Centres Responding to Survey

\begin{tabular}{lc} 
Province & No. of Respondents \\
\hline Newfoundland & 1 \\
Nova Scotia & 1 \\
New Brunswick & 2 \\
Quebec & 1 \\
Ontario & 10 \\
Within Toronto & 4 \\
Outside Toronto & 6 \\
Manitoba & 2 \\
Saskatchewan & 2 \\
Alberta & 5 \\
British Columbia & 7 \\
Within Lower Mainland & 3 \\
Outside Lower Mainland & 4 \\
\hline Total & 31
\end{tabular}

physician. In 16 (52\%) of the units, time was allocated during rounds for the pharmacist to present; in the remainder of the units, pharmacists were expected to support and comment on presentations by other members of the team. Respondents indicated that pharmacists' most common contributions during rounds were reviewing current medications, reviewing antimicrobial therapy, adjusting medication dosing for organ dysfunction, providing therapeutic drug monitoring, and ensuring appropriate prophylaxis (Figure 1). These reported pharmacist activities during rounds aligned with the "fundamental" and "optimal" activities for clinical pharmacists outlined by the Society of Critical Care Medicine and the American College of Clinical Pharmacy. ${ }^{1,2}$ Clinical pharmacists transcribed orders from rounds consistently in $3(10 \%)$ of the units (specifically those in the Lower Mainland of British Columbia) and on a dependent basis in another $5(16 \%)$ of the units.

Respondents reported that pharmacists prepared for rounds using checklists in $10(32 \%)$ of the centres, with FASTHUG ${ }^{6}$ being the most common checklist. The majority of pharmacist documentation occurred as shadow charting, with 25 (81\%) of respondents reporting that this documentation was not included in the medical record; for example, 17 (55\%) of the centres reported use of a standardized patient monitoring form. In $27(87 \%)$ of the units, pharmacists relied on the progress notes of other team members to record their contribution during rounds in the medical record, and 57\% (17/30) of respondents reported that they would supplement those notes if they were discordant with the care decision made or if the pharmacist determined that further detail was necessary. Pharmacists spent much effort creating shadow charting, which is shared solely among pharma- 


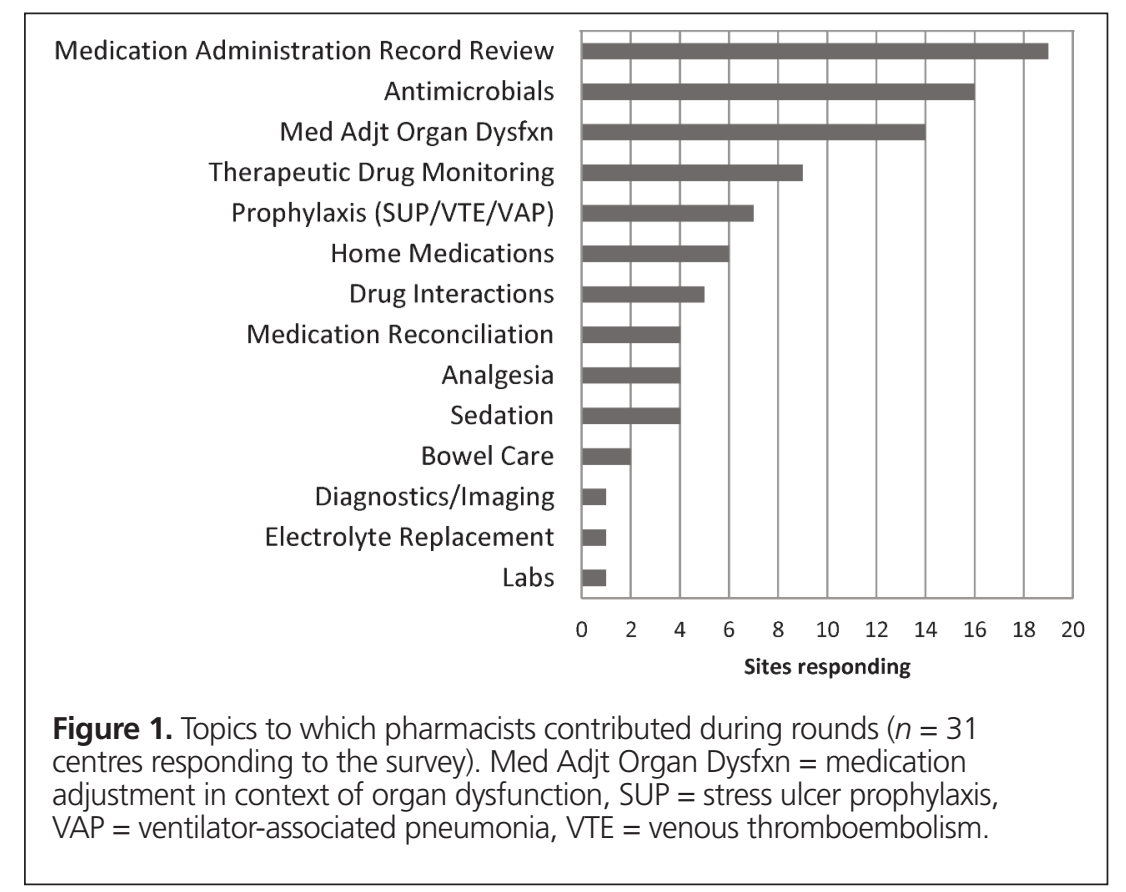

cists. Shadow charting may be leftover from a time before computer information systems, when pharmacists rarely attended the ward and conducted consultations over the telephone. Institutions should review the efforts expended on shadow charting, with a view to ensuring that pharmacists' assessments and actions are included in the formal medical record.

These results show that Canadian pharmacists' selfdescription of their practice in the ICU is variable and poorly defined, with clinicians often describing their practice as being dependent on specific patient requirements. Clinical coverage models, patient load, and pharmacist training levels also differ. Documentation of drug therapy decisions largely relies on physicians' progress notes, and the majority of pharmacist documentation occurs outside the legal record. However, clinical pharmacists are commonly expected to document their interventions, and doing so has been shown to have benefits in terms of cost avoidance. ${ }^{1,7,8}$ Work, research, and programming to decrease barriers to pharmacist documentation are ongoing. ${ }^{9,10}$ The sample in this survey study may have been too small to show statistically significant practice differences in relation to centre characteristics. This sample may also not be reflective of all centres in Canada, as there was likely selection bias among the participants; however, the findings may serve as a baseline for future environmental scans of ICU practice in Canada.

\section{References}

1. Society of Critical Care Medicine; American College of Clinical Pharmacy; Rudis MI, Cohen R, Cooper BE, Gonzalez LS, Hassan E, Klem C, et al. Position paper on critical care pharmacy services. Pharmacotherapy. 2000; 20(11):1400-6.

2. MacLaren R, Devlin JW, Martin SJ, Dasta JF, Rudis MI, Bond CA. Critical care pharmacy services in United States hospitals. Ann Pharmacother. 2006; 40(4):612-8.
3. Preslaski CR, Lat I, MacLaren R, Poston J. Pharmacist contributions as members of the multidisciplinary ICU team. Chest. 2013;144(5):1687-95.

4. Leguelinel-Blache G, Nguyen TL, Louart B, Poujol H, Lavigne JP, Roberts JA, et al. Impact of quality bundle enforcement by a critical care pharmacist on patient outcome and costs. Crit Care Med. 2018;46(2):199-207.

5. SHPA Committee of Specialty Practice in Critical Care; Leung D, Kirsa S, Egan A, Milne D, Lau R, Lum E, et al. SHPA standards of practice for critical care pharmacy practice. J Pharm Pract Res. 2008;38(1):58-60.

6. Mabasa VH, Malyuk DL, Weatherby EM, Chan A. A standardized, structured approach to identifying drug-related problems in the intensive care unit: FASTHUG-MAIDENS. Can J Hosp Pharm. 2011;64(5):366-9.

7. Lada P, Delgado G Jr. Documentation of pharmacists' interventions in an emergency department and associated cost avoidance. Am J Health Syst Pharm. 2007;64(1):63-8.

8. ASHP Council on Pharmacy Practice. ASHP guidelines: minimum standard for pharmacies in hospitals. Am J Health Syst Pharm. 2013;70(18):1619-30.

9. Rector KB, Veverka A, Evans SK. Improving pharmacist documentation of clinical interventions through focused education. Am J Health Syst Pharm. 2014;71(15):1303-10.

10. Pullinger W, Franklin BD. Pharmacists' documentation in patients' hospital health records: issues and educational implications. Int J Pharm Pract. 2010; 18(2):108-15.

Jonathan F Mailman, BSC(Pharm), ACPR, PharmD, CD

Clinical Pharmacist Specialist

Saskatchewan Health Authority - Regina

Clinical Lecturer

College of Medicine, University of Saskatchewan

Regina, Saskatchewan

William Semchuk, MSc, PharmD, FCSHP

Manager, Clinical Pharmacy Services

Director, Hospital Pharmacy Residency Program

Saskatchewan Health Authority - Regina

Regina, Saskatchewan

Competing interests: None declared.

Funding: None received.

Acknowledgement: The authors wish to acknowledge Ali Bell for statistical analysis support. 